\title{
Health and Sustainability: New Gender Perspectives
}

\author{
FRANCESCA DONOFRIO $^{1}$, ANTONIO FUSCO ${ }^{2}$, ANGELAMARIA DE FEO \\ ${ }^{1}$ Department of Economics, Management and Business Law \\ University of Bari Aldo Moro \\ Largo Abbazia di Santa Scolastica n. 53, 70124, Bari, ITALY \\ ${ }^{2}$ Department of Economics, Management and Business Law \\ University of Bari Aldo Moro \\ Largo Abbazia di Santa Scolastica n. 53, 70124, Bari, ITALY \\ ${ }^{3}$ Department of Psychology, Education and communication \\ University of Bari Aldo Moro \\ Palazzo Chiaia-Napolitano - Via Scipione Crisanzio n. 42, 70122, Bari, ITALY
}

\begin{abstract}
European health systems face important challenges related to the sustainability of health care, both from an economic point of view and in relation to the quality of health services provided in terms of continuous improvement of effectiveness, safety, clinical and organisational appropriateness. The ability of EU Member States to continue to provide high quality care to all, whatever their biological and socio-cultural characteristics, depends on their health systems becoming more sustainable. Therefore, there is a need to strengthen health promotion and disease prevention, to invest in primary care systems, to move health care out of the hospital and into more accessible ambulatory and domestic care, and to develop integrated care practices.

Starting from these premises, the aim of this paper is to present a narrative overview of the main aspects related to Gender Medicine and its evolution over time. Our critical overview is, therefore, aimed at providing a general picture of what has been developed by health systems on Gender Medicine, with a particular focus on the relationship between social sustainability and Gender Medicine.

To achieve our goal, we carry out a systematic literature review in order to understand what has been developed so far in the area and to highlight the possible evolution of studies in the field and to strengthen the awareness of the importance of encouraging prevention, training and information programs shared with hospitals, institutions, health professionals and patient associations.

To the best of the authors' knowledge, this is among the first studies that investigate through a systematic literature review the phenomenon of gender medicine, especially with reference to the sustainability of the health care system. Although our analysis needs further investigation, due to the fact that the topic is not yet fully mature, our initial and preliminary results underline the importance of further investigating gender diversity and assessing the possibility of promoting a clinical pathway to personalised treatment. In fact, only through a "gender medicine" approach it is possible to guarantee a real right to health and an effective personalisation of treatments, thus reinforcing the concept of patient focussed care and contributing to the sustainability of the whole health system.
\end{abstract}

Key-Words: - Health care system, sustainability, gender medicine, gender health medicine, performance, female, male, gender determinants, Systematic Literature Review

Received: November 18, 2020. Revised: May 2, 2021. Accepted: May 14, 2021. Published: May 21, 2021.

\section{Introduction}

Going beyond the traditional notion of gender as a set of unchanging biological characteristics that identify men and women, since the 1990s medicine has extended its frontiers by introducing additional variables of investigation. These variables refer not only to biological differences, but also to sociocultural ones. The inclusion and consideration of socio-cultural issues has led to the emergence of a 
new field of Medicine, the so-called "Gender Medicine" [1].

A process based on equal opportunities was therefore begun, and in this context the issue of gender was given a prominent role in health care initiatives from an economic, social and psychological perspective. In the 1980s, the United Nations Organisation issued a special Convention "Committee on the Elimination of Discrimination against Women" to overcome biological and gender differences linked to socioeconomic and cultural conditions and to guarantee equal access to health services without any restrictions. In 2002, the World Health Organisation (WHO) also set up The Department of Gender and Women's Health $(\mathrm{GWH})$ confirming the presence of gender differences, mainly related to cultural and social data, that influence the health status of men and women. In 2007, the European Community established the European Institute of Women's Health (EIWH) and then, in 2011, the European Institute for Gender Equality (EIGE) in which gender was beginning to play a significant role in medical studies. In 2010, the European Community adopted the "Women's Charter", which enhances the principle of equality between men and women as a fundamental right and a key value for democracy. For about a ten-year period, medicine has been seen in a new way from the perspective of gender and foresees that in the future there will be two different ways, one for the treatment of men, one for the treatment of women with the focus on identifying differences and similarities in a parallel process [2]. In 2017, in Brussels, the European Parliament hosted the Round Table "Towards a gender sensitive medicine: matters, tools and policies. Good practices from Italy and Germany", to launch a debate oriented to ensure the diffusion of a gender approach in the policies and strategies of the health systems of each Member State [3].

In line with these considerations, it is evident that the organisations' approach to Gender Medicine is increasingly oriented towards a widening of the focus from the protection of women's health and a greater weighting of biological, social, cultural, economic and environmental variables in determining the health status of people (men and women), so as to integrate the perspectives of equity and respect for human rights by promoting more effective and efficient health systems.

Therefore, there is now a need to strengthen health promotion and disease prevention, to invest in primary care systems, to shift health care from the hospital to more accessible ambulatory and home care, and to develop integrated care practices. In this sense, this paper aims at presenting an overview of the main aspects related to Gender Medicine and what has been developed by health systems on Gender Medicine. With particular reference to the issue of sustainability, this paper aims to understand if Gender Medicine impacts on the sustainability of the Health Care System and in particular on its social sustainability. More specifically, we intend to answer the following research question: How does gender impact social sustainability in health care?

In order to achieve our goal, we carry out a systematic review of the literature in order to understand what has been developed in the subject so far, to highlight the possible evolution of studies in the area and to raise awareness of the importance of encouraging prevention, education and information programmes shared with hospitals, institutions, health professionals and patient associations.

\section{Methodology}

In order to achieve our goal and to systematically define the role of gender in the health care system, we conduct a systematic literature review (SLR). [4] Unlike the "traditional literature review"[5], the SLR allows us to generate an independent view on the topic[6]. The SLR has the potential to provide an opportunity to bring together previous literature and build strong definitions and develop insights for future research [5].

For the development of an SLR, a series of predefined steps are followed for literature review. Indeed, it is this aspect that ensures the reproducibility of the process. More precisely, the process consists of the following four main steps: (i) planning the review; (ii) identifying and evaluating articles; (iii) extracting and synthesizing data; and (iv) disseminating the review results.

\section{Planning}

The decision to undertake a SLR focusing on the relationship between Gender Medicine and health system sustainability is driven by several reasons. Firstly, we considered the need to undertake this SLR as, to the best of our knowledge, there is no SLR on the topic to date. In this sense, our study is innovative as, given the growing importance of the chosen topic, we believe that the impact of gender medicine on health system sustainability should be studied systematically.

In order to provide a high-quality and clear process, our research team established a review protocol and looked for instances in which the words "gender medicine" and "sustainability" and "health care" occurred in the title, abstract, or keywords of an article. We have undertaken this searching in Elsevier's Scopus database. Thus, we excluded from 
our search any conference proceedings, book chapters, book reviews, conference abstracts, theses, interviews, and any type of article which was not written in English. Furthermore, we restricted the search to the areas of business, management, and accounting as important research streams. The final results include 73 research articles related to the objectives of this SLR.

\section{Analysis and identification of articles}

We reviewed the titles, keywords and abstracts of our 73 retrieved research articles, keeping in mind the best connection each had with our research objectives. This step of the research was taken as we revised our records, which were duly collated in an MS Excel database. Our evaluation process consisted of seven steps. Initially, we analysed the title, keywords and abstract of each article and excluded those unrelated to our research. Next, we screened the full text of the articles and further filtered our results (Table 1).

Table 1 - Definition of relevant papers

\begin{tabular}{|l|r|}
\hline & Results \\
\hline Total paper from Scopus & 73 \\
\hline - Irrelevant titles, keywords, and abstracts & 45 \\
\hline Total articles analyzed in full text & 28 \\
\hline - Not relevant paper & 8 \\
\hline Total paper considered & 20 \\
\hline
\end{tabular}

Source - Elaborated by authors

To ensure the highest reliability, each of the steps mentioned above was carried out separately by each research team member. After the comparison of each member's findings with the others, the team approved the final database. As a result, a total of 20 research articles were included as correct sources for the SLR (Table 2). clearly, this research stream is quite nascent.

Table 2 - List of articles considered

\begin{tabular}{|c|c|c|}
\hline No. & $\begin{array}{l}\text { Authors } \\
\text { (year) }\end{array}$ & Title \\
\hline 1 & $\begin{array}{l}\text { Hyde E.et al. } \\
\text { (2021) }\end{array}$ & $\begin{array}{l}\text { Estimating the local spatio- } \\
\text { temporal distribution of malaria } \\
\text { from routine health information } \\
\text { systems in areas of low health } \\
\text { care access and reporting }\end{array}$ \\
\hline 2 & $\begin{array}{l}\text { Liu N.et al. } \\
(2020)\end{array}$ & $\begin{array}{l}\text { Dual effects of social support } \\
\text { seeking in patient-centric online }\end{array}$ \\
\hline
\end{tabular}

\begin{tabular}{|c|c|c|}
\hline & & $\begin{array}{l}\text { healthcare communities: A } \\
\text { longitudinal study }\end{array}$ \\
\hline 3 & $\begin{array}{l}\text { Gauld R.et al. } \\
(2020)\end{array}$ & $\begin{array}{l}\text { Did healthcare professional } \\
\text { perspectives on the quality and } \\
\text { safety environment in New } \\
\text { Zealand public hospitals change } \\
\text { from } 2012 \text { to } 2017 ?\end{array}$ \\
\hline 4 & $\begin{array}{l}\text { Ihantamalala } \\
\text { F.A.et al. } \\
\text { (2020) }\end{array}$ & $\begin{array}{l}\text { Improving geographical } \\
\text { accessibility modeling for } \\
\text { operational use by local health } \\
\text { actors }\end{array}$ \\
\hline 5 & $\begin{array}{l}\text { Arul U. } \\
(2020)\end{array}$ & $\begin{array}{l}\text { Access to healthcare facilities } \\
\text { among the disabled people } \\
\text { towards the public healthcare } \\
\text { institution }\end{array}$ \\
\hline 6 & $\begin{array}{l}\text { Son J.et al. } \\
(2020)\end{array}$ & $\begin{array}{l}\text { A data analytics framework for } \\
\text { smart asthma management } \\
\text { based on remote health } \\
\text { information systems with } \\
\text { bluetoothenabled personal } \\
\text { inhalers }\end{array}$ \\
\hline 7 & $\begin{array}{l}\text { Sivaranjani } \\
\text { P.et al. } \\
(2020)\end{array}$ & Automatic medicine teller \\
\hline 8 & $\begin{array}{l}\text { Spano A.et } \\
\text { al. }(2020)\end{array}$ & $\begin{array}{l}\text { Performance and expenditure in } \\
\text { Italian public healthcare } \\
\text { organizations: does expenditure } \\
\text { influence performance? }\end{array}$ \\
\hline 9 & $\begin{array}{l}\text { Park H.et al. } \\
(2019)\end{array}$ & $\begin{array}{l}\text { The motivations of external } \\
\text { whistleblowers and their impact } \\
\text { on the intention to blow the } \\
\text { whistle again }\end{array}$ \\
\hline 10 & $\begin{array}{l}\text { Kordts B.et } \\
\text { al. }(2019)\end{array}$ & $\begin{array}{l}\text { Requirements and Interaction } \\
\text { Patterns for a Novel Interaction } \\
\text { Device for Patients in Intensive } \\
\text { Care }\end{array}$ \\
\hline 11 & $\begin{array}{l}\text { Kalaitzi S.et } \\
\text { al. (2019) }\end{array}$ & $\begin{array}{l}\text { Women, healthcare leadership } \\
\text { and societal culture: A } \\
\text { qualitative study }\end{array}$ \\
\hline 12 & $\begin{array}{l}\text { Tomaselli } \\
\text { G.et al. } \\
\text { (2018) }\end{array}$ & $\begin{array}{l}\text { Healthcare systems and } \\
\text { corporate social responsibility } \\
\text { communication: A comparative } \\
\text { analysis between Malta and } \\
\text { India }\end{array}$ \\
\hline 13 & $\begin{array}{l}\text { Bahrampour } \\
\text { M.et al. } \\
\text { (2018) }\end{array}$ & $\begin{array}{l}\text { Hospital service quality - } \\
\text { patient preferences - a discrete } \\
\text { choice experiment }\end{array}$ \\
\hline 14 & $\begin{array}{l}\text { Al-Amin } \\
\text { M.et al. } \\
\text { (2018) }\end{array}$ & $\begin{array}{l}\text { Sustained hospital performance } \\
\text { on hospital consumer } \\
\text { assessment of healthcare } \\
\text { providers and systems survey } \\
\text { measures: What are the } \\
\text { determinants? }\end{array}$ \\
\hline
\end{tabular}




\begin{tabular}{|c|c|c|}
\hline 15 & $\begin{array}{l}\text { Mukred A.et } \\
\text { al. (2017) }\end{array}$ & $\begin{array}{l}\text { Investigating the impact of } \\
\text { information culture on the } \\
\text { adoption of information system } \\
\text { in public health sector of } \\
\text { developing countries }\end{array}$ \\
\hline 16 & $\begin{array}{l}\text { Schwartz } \\
\text { D.G.et al. } \\
(2017)\end{array}$ & $\begin{array}{l}\text { Exploring mHealth } \\
\text { participation for emergency } \\
\text { response communities }\end{array}$ \\
\hline 17 & $\begin{array}{l}\text { Beckett R.C. } \\
(2017)\end{array}$ & $\begin{array}{l}\text { Hearing enhancement } \\
\text { technologies and issues of self- } \\
\text { management: A case study }\end{array}$ \\
\hline 18 & $\begin{array}{l}\text { Gibbons J.et } \\
\text { al. (2016) }\end{array}$ & $\begin{array}{l}\text { Determining the spatial } \\
\text { heterogeneity underlying racial } \\
\text { and ethnic differences in timely } \\
\text { mammography screening }\end{array}$ \\
\hline 19 & $\begin{array}{l}\text { Roth V.R.et } \\
\text { al. }(2016)\end{array}$ & $\begin{array}{l}\text { Women physicians as } \\
\text { healthcare leaders: a qualitative } \\
\text { study }\end{array}$ \\
\hline 20 & $\begin{array}{l}\text { Sullivan } \\
\text { E.E.et al. } \\
(2016)\end{array}$ & $\begin{array}{l}\text { Management lessons for high- } \\
\text { functioning primary care teams }\end{array}$ \\
\hline
\end{tabular}

Source - Elaborated by authors

\section{Data extraction and summary}

To perform the data extraction, we created a search list within the Scopus database that included the 20 research articles mentioned above. Therefore, we generated a comma-delimited values (CSV) file in MS Excel format to be used in the next step. For our purposes, this MS Excel CSV file provides the following information.

- Citation information: authors, title of paper, source and type of paper, stage of publication, number of citations, DOI;

- Bibliographic information: affiliations, serial identifiers, PubMed ID, publisher, language of the original paper, correspondence address;

- Abstracts and keywords.

We adopted the VOSviewer software [7] to provide keyword and content analyses and present our data synthesis results in line with several descriptive bibliometric analyses [8]. Our bibliometric analysis using VOSviewer is mainly based on cluster analysis using co-occurrence of keywords, document citations and bibliographic coupling.

\section{Disclosure of analysis results}

Our SLR is the first to draw connections between gender medicine and health system sustainability; as such, it provides valuable, cutting-edge information [5] that advances studies on health system management.

\section{Results}

In this section, we report our results in response to our research question and also provide a bibliometric and narrative review of the articles in our database. We began our descriptive analysis with determining the distribution of the 20 research articles selected, both in terms of publication time and geographical location. Although the nature of this field of research is still relatively immature, the trend in the literature on the subject is increasing. From the systematic analysis of the literature carried out, there has been a $133 \%$ increase in studies on the topic over the period of analysis. Indeed, articles increased from 3 in 2016 to 7 in 2020 ( 1 in 2021). For each article, we identified the affiliation to which the first author belongs, and found that the distribution is mainly concentrated on economically advanced countries. The United States is at the top of this list, with five research articles each. We undertook an occurrence analysis by identifying the most relevant author keywords among the 20 research articles. Table 2 presents these keywords, each of which has a minimum of three occurrences. "Human" (22 occurrences), "Health Care" (15 occurrences) and "Female" (11 occurrences) are important keywords that often come up when analysing and responding to our RQ.

Table 3 - Author's keywords occurrences

\begin{tabular}{|l|c|}
\hline keywords & Occurrences \\
\hline Human & 22 \\
\hline Health Care & 15 \\
\hline Female & 11 \\
\hline Male & 8 \\
\hline Leadership & 6 \\
\hline Health Care Quality & 5 \\
\hline Health Care Personnel & 4 \\
\hline Human Experiment & 4 \\
\hline Patient Satisfaction & 4 \\
\hline Efficiency, Organizational & 3 \\
\hline Health Policy & 3 \\
\hline Information Processing & 3 \\
\hline Patient Care & 3 \\
\hline Primary Health Care & 3 \\
\hline Program Evaluation & 3 \\
\hline \multicolumn{2}{|c|}{ Source - Elaborated by authors } \\
\hline
\end{tabular}


Next, we investigated all keyword clusters by examining the co-occurrence of all keywords, choosing three as the minimum number of keyword occurrences (Figure 1).

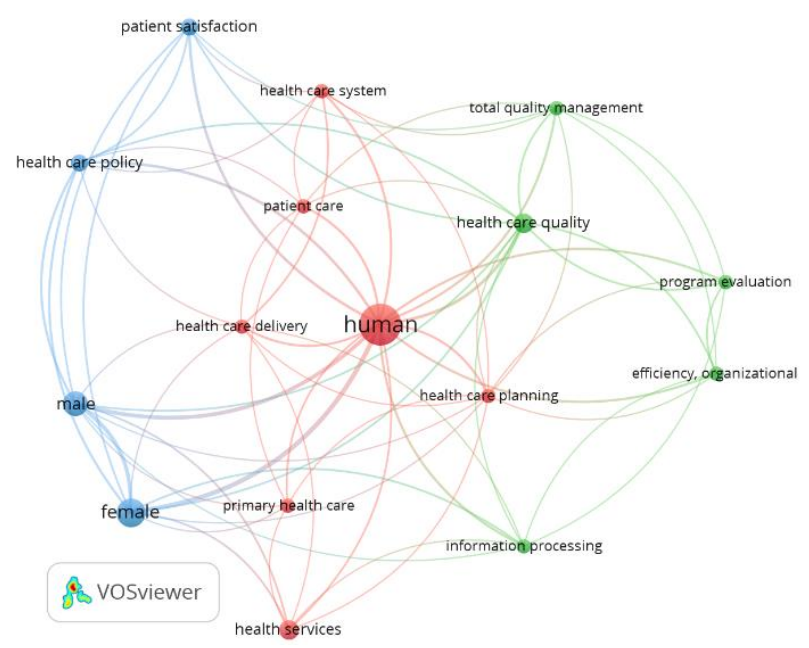

Figure 1 - Keywords occurrence Source - Elaborated by authors

Table 3 shows the groupings of keyword occurrences, which identify three clusters. We identified cluster 1 (seven items, red colour), cluster 2 (five items, green colour) and cluster 3 (four items, blue colour).

Interestingly, our results highlight two main search streams that align with the keywords we used to undertake our literature search on Scopus. The results are interesting and relate directly to i) female with human, healthcare quality, healthcare planning and primary healthcare; ii) health care quality with female, male, healthcare policy healthcare planning. With regards to the first group, composed by 7 items, the relevant trait is to provide high quality health care in order to meet the needs of patients, with specific reference to gender aspects, and enable an improvement in the relationship between patients and physicians [9]-[12]. The doctor-patient relationship is crucial, so much so that even in the absence of healthcare facilities in most countries with a high incidence of disease, patients rely on passive surveillance systems based on facilities [13]. The second group consists of 5 articles and includes all those documents that focus on aspects of health organisation and planning and their impact on the quality of care [11], [14]-[17]. Finally, the last cluster consists of 4 items. it is a marginal cluster compared to the first two and the papers in this group do not have a single focus, varying from gender to quality of care and patient satisfaction [9], [18], [19].

Table 4 - Cluster of keywords occurrence keyword Occurences

\begin{tabular}{clr} 
& keyword & Occurences \\
& Human & 22 \\
& Health Care delivery & 3 \\
Cluster 1 & Health Care planning & 3 \\
& Health Care system & 3 \\
& Health services & 5 \\
& Patient care & 3 \\
& Primary Health Care & 3 \\
\hline & Efficiency, Organizational & 3 \\
& Health care quality & 5 \\
Cluster 2 & Information Processing & 3 \\
& Program Evaluation & 3 \\
& Total quality management & 3 \\
\hline & Female & 11 \\
Cluster 3 & Health care policy & 4 \\
& Male & 8 \\
& Patient Satisfaction & 4
\end{tabular}

Source - Elaborated by authors

The following table (Table 4) summarises, for each article considered, the number of citations obtained. More specifically, the research articles that garnered the most interest and had the most influential authors were those by Sullivan et al. (2016) and Roth et al. (2016).

Specifically, Sullivan et al. (2016) offer a semistructured literature review, based on the management and health care literature, that summarizes and applies team frameworks and best practices from the past 35 years to the existing primary care scenario. Management strategies that are relevant to primary care teams typically include teaming, working with existing teams, and patientbased teams. The literature on management provides a range of recommendations for building professional successful teams, such as rethinking goals, encouraging shared decision making, communicating effectively, learning from failures, and using organizational structures to support multidisciplinary teams. Among the major barriers, the authors include system-level barriers to effective communication and efficiency, prioritizations, lack of time and financial incentives, asymmetry of information and interests, and the complexity of working with people with different backgrounds. The authors recommend creating teams, deconstructing the current practice hierarchy, promoting cultural change, creating role 
clarity for health care managers and team members, and encouraging team-based care.

Roth et al. (2016) study the representation of women in leadership positions in the healthcare system. The authors report that participants perceived an organisational culture that was resistant and reluctant to change. It lacked both gender and cultural diversity and they felt that a more intentional inclusion of different types of leaders would result in a healthier organisation. Roth et al. provide empirical insights into the determinants of the presence or absence of women in leadership positions. Among the main barriers, the authors highlight limitations related to the mismatch between costs and benefits, as well as the underestimation of leadership by medical peers and the perceived lack of support from nursing.

Table 5 - Citations per authors/document

\begin{tabular}{|l|c|}
\hline Research paper & No. of citations \\
\hline Hyde E. (2021) & 0 \\
\hline Liu N. (2020) & 1 \\
\hline Gauld R. (2020) & 1 \\
\hline Ihantamalala F.A. (2020) & 0 \\
\hline Arul U. (2020) & 0 \\
\hline Son J. (2020) & 3 \\
\hline Sivaranjani P. (2020) & 0 \\
\hline Spano A. (2020) & 3 \\
\hline Park H. (2019) & 0 \\
\hline Kordts B. (2019) & 8 \\
\hline Kalaitzi S. (2019) & 0 \\
\hline Tomaselli G. (2018) & 2 \\
\hline Bahrampour M. (2018) & 0 \\
\hline Al-Amin M. (2018) & 1 \\
\hline Mukred A. (2017) & 2 \\
\hline Schwartz D.G. (2017) & 1 \\
\hline Beckett R.C. (2017) & 0 \\
\hline Gibbons J. (2016) & 0 \\
\hline Roth V.R. (2016) & 11 \\
\hline Sullivan E.E. (2016) & 31 \\
\hline \multicolumn{2}{|c|}{ Source - Elaborated by authors } \\
\hline
\end{tabular}

\section{Discussion}

The study of differences between the genders and the development of gender-specific medicine is now a major landmark in the progress of life sciences. Gender medicine, or gender-specific medicine, consists of the study of the influence of sex and gender, a term that also covers socio-cultural and psychological aspects, on the physiology and diseases that affect both men and women. Gender differences can be observed in the frequency, symptoms and severity of many diseases and also in the response to treatment and adverse reactions to drugs. Gender differences in lifestyles, which often differ between men and women, and in response to nutrients and environmental contaminants are also very important determinants of health. Even when looking at the aspect of aging and related diseases, gender takes on a predominant role. Men and women differ not only biologically, but also in terms of lifestyle (level of education, work occupation, diet, physical activity, etc.) and attitude to dealing with stressful situations [20]-[22]. A gender approach in clinical practice can contribute significantly to health promotion by improving the appropriateness of care, which can benefit both patients and the sustainability of the Health Service [23]. In this sense, sustainability in healthcare can be understood in terms of quality care provided to patients, responsible financing and minimal environmental impact [23], [24]. With regard to the first aspect, the main priority of health care institutions is to provide adequate and appropriate care to patients. A gender-based approach that takes into account not only gender but also socio-cultural characteristics will allow for a better understanding of patients' needs and requirements, so as to respond more effectively to them and define care more precisely and therefore more sustainably. In fact, the absence of specific treatment shows how crucial it is to study the link between pathology and gender and to outline the critical issues related to hormonal and genetic issues, as well as the correlation between pathology and gender in comorbid conditions. The aim is to understand the mechanisms through which gender differences affect individuals in order to understand and plan effective responses [25]. Secondly, as regards financial stability, all institutions, in order to be sustainable, must be able to cover all costs (provision of services, maintenance and salaries) from their own revenues[23], [26]. Finally, with regard to environmental costs, health professionals have an obligation to consider the environmental impact of their work, in terms of emissions, waste and disposal [23], [26].

Geographical accessibility to health facilities remains a major barrier to accessing care in rural areas of the developing world [27]-[29]. Although there are methods and tools to model geographical accessibility, the lack of basic geographical information prevents its widespread use at local level. Indeed, currently one-half of the world's population continues to lack access to essential health services. Poor access to health care in rural areas of the developing world is due to a combination of financial, geographical and health system barriers [30]-[32]. A Gender Approach is even more needed in neglected countries, where women's conditions are worse and gender differences are stronger and have a 
greater impact on health status. In this sense, gender should be at the centre of the clinical approach. With this in mind, a radical cultural change and reorganization of clinical services in all countries and health systems is required [20]. To reduce the impact that weak health systems and user fees have on access to health care, there is a growing consensus around the central role of sectoral approaches such as health system strengthening and universal health coverage [33]. An increasingly recognised pillar is the role of health workers in reducing geographical inequalities in access and ensuring the provision of primary care at community level [34]. The use of primary care is tending to decrease exponentially with increasing distance from health structures, a phenomenon known as "distance decline" [13], [35], [36]. Distance and travel time to primary health care centres, especially in rural areas, are recognised care utilisation factors, which show consistent negative impacts on the use of antenatal, perinatal and obstetric care for women [37], [38].

Added to this are the disparities in screening along racial and ethnic lines that persist between different countries. The role of local context, as identified through spatial heterogeneity, is an unexplored dynamic that explains some of the gaps in screening along racial and ethnic lines. This inconsistency requires health professionals and outreach services to be aware of local context in their planning and resource allocation efforts [10].

Another key aspect to consider when talking about access to care is the cultural sphere. Prevailing barriers include work-life balance, lack of family support, culture, stereotypes, gender prejudice and lack of social support. Indeed, in a family-centred cultural context, one cannot overlook the burden of care that falls on women, even if they are workers, and which, in the absence of a division of roles, is reflected in a progressive risk of chronic and disabling pathologies as the family load increases [39]-[41]. Domestic work, besides being emotionally and physically exhausting, reduces the time a woman can devote to herself and her rest [41], but also to training. The consequence is that while women's employment could counteract income inequalities [42], it generates new negative influences on their health due to the dual commitment to family and work. In the context of European forecasts, further risks emerge in connection with new forms of employment contracts and job insecurity, which is considered a source of worry and stress that negatively affects health status [43]-[45]. In general, socio-environmental security is expressed in terms of economic, personal, social, intellectual, environmental, physical and occupational security.
These elements characterize "the social protection of personnel, the development of intellectual potential, environmental compliance, health care, and the protection of a company's property and reputation" [45].

Similarities between countries and differences in the prevalence of the barriers identified were observed [46]. The workplace environment is known to influence professional attitudes towards quality and safety [18], [47].

Among the socio-economic indicators, work thus plays a fundamental role in the lives of individuals and consequently affects their well-being. The working man and woman and the environment in which they work must be studied and analysed in terms of the many aspects and risk factors that are closely linked to the characteristics of the workers (gender, race, age, country of origin).

While work provides income, it may also generate frustration [48] and unemployment [44], [48], especially in low-skilled, repetitive and low-paid occupations [44], [49].

In fact, high work rhythms, stress, disorganisation, lack of recognition for the work done, etc., are all factors that have a negative impact on the health of each individual. These factors, if persistent, can lead to the emergence of stress situations [50]. It is also not uncommon for work to take place in work environments where safety features in terms of monitoring the degree of worker fatigue and tiredness, exposure to dust and harmful chemicals, noise and other factors are almost completely absent. With regard to the latter, greater attention is being paid to typically male jobs, although it should be remembered that women's jobs also need to be monitored [41], [51], the risks of which remain largely invisible, as do the unequal consequences for health [52].

Potential barriers to health care include the undervaluing of leadership by medical peers and the perceived lack of support from nurses [15]. Healthcare leaders and managers have only an emerging understanding of how to create highfunctioning primary care teams. Management scholars have studied and debated the fundamentals of high-functioning teams over the past decades in a variety of sectors, and it is critical that primary care providers adopt management lessons to provide better interprofessional care [16]. Relevant management strategies for primary care teams include teaming, working with existing teams and patient-based teams. The management literature presents a number of recommendations for creating successful professional teams, such as rethinking goals, promoting shared decision-making, 
communicating effectively and interprofessionally, clarifying roles, learning from failures, and using organisational structures to support multidisciplinary teams. Common barriers include system-level obstacles to communication and efficiency, hierarchies, lack of time and financial incentives, asymmetry of information and interests, and the complexity of working with people from different backgrounds. In this sense, an increasing focus on health CSR communication enables health care organisations to reduce information asymmetry problems, by using interactive technologies that allow several advantages to organisations over traditional tools (such as better dialogue and interaction with different stakeholders, speed, low costs, easy access to information), as well as requiring investments and costs in infrastructure and skills/competencies for their implementation [17], [45], [53], [54].

Despite the importance of information literacy, little is known about the influence of information literacy on the adoption of information systems (IS) among employees in the public health sector in developing countries. Self-efficacy, social influence, performance expectancy and perceived access significantly influence employees' intention to adopt IS. However, perceived need, perceived information sharing and perceived effort expectancy significantly influence attitude, which in turn influences their behavioural intention. In addition, perceived awareness negatively influences behavioural intention. Moreover, facilitation conditions and effort expectancy did not have a significant influence on employees' behavioural intention [55].

On the contrary, the adoption of IT systems based on new technologies can help to improve patient satisfaction [12], [19], [56]-[59].

Reliable surveillance systems are essential for identifying disease outbreaks and allocating resources to ensure universal access to diagnosis and treatment of endemic diseases. Although there is a lack of health facilities in most countries with a high incidence of disease, patients rely on facility-based passive surveillance systems [13]. Understanding the dynamics of local disease from routine passive surveillance data can be a key step towards achieving universal access to diagnosis and treatment [14].

High quality health care is important for all patients. If health care is perceived to be of high quality, patients will be satisfied and the relationship between patients and health professionals will improve. Patient satisfaction is among the most commonly used indicators of service quality; however, it is not fully known what factors influence patient satisfaction [9]. Therefore, it is necessary to pay attention to the elements that influence both the quality of health care and patient satisfaction. Nowadays, several methods are used in health economics to assess patient preferences, set priorities and help health policy makers to improve services [9], [11], [60].

\section{Conclusion}

Gender Medicine is taking a central position in the scientific-academic debate. Indeed, starting from the assumption that a greater attention to gender influenced by the intersectionality of different factors such as ethnicity, lifestyles, socio-economic and cultural conditions - would allow to correctly reinterpret pathologies, define prevention and treatment activities, Gender Medicine would contribute to the improvement of health, to a better allocation of economic resources and therefore to a cost-effectiveness optimisation. The analysis showed that it would be useful and a priority to further investigate gender-related differences and to evaluate the possibility of undertaking a pathway of personalisation of therapies in order to ensure not only good efficacy but also greater safety of clinical treatments.

It is clear that only through a gender approach to medicine can the right to health and the personalisation of care be protected, ensuring the centrality of the patient, with his or her biological, cultural, ethnic and social characteristics. Consequently, health spending would also be based on criteria of equity, transparency and effectiveness. Indeed, good planning will make it possible to better anticipate, prepare for and meet future health care demands. Moreover, the provision of high-quality care will depend on the ability of health systems to become more resilient and sustainable in economic, social and environmental terms.

The healthcare system's short-term objective is to achieve economic (cost-effectiveness) and financial sustainability without compromising the quality of the treatments provided. During periods of withdrawal, such as the current health economic crisis caused by the Covid-19 pandemic, spending cuts and ceilings or tight controls on prices and volumes are often adopted. While these measures are more or less effective in ensuring the financial sustainability of health expenditure in the short term, they may not be able to adequately control the main drivers of expenditure growth in the long term, and they present risks in terms of maintaining quality and equity levels in health care systems.

In conclusion, sustainable healthcare is a combination of three key factors: quality care provided to patients, responsible fiscal financing, and 
minimal environmental impact. With regard to the first aspect, the principal priority of health institutions is to provide adequate and appropriate care to patients. Moreover, any sustainable health project must respect the patients' needs and the professionals' sense of responsibility and competence. Secondly, with regard to financial equilibrium, all institutions, in order to be sustainable, must be able to cover all costs from their own revenues. Finally, with regard to environmental costs, health professionals have an obligation to consider the environmental impact of their work, in terms of emissions, waste and disposal.

In conclusion, Gender Medicine has to be conceived as a transversal integration of medical specialities and competences, in order to create a culture that puts the patient at the centre of attention and that takes into account gender differences in clinical activities, not only from an anatomical-physiological point of view, but also from a biological-functional, psychological, socio-economic and cultural point of view. The issue of gender should be central to the clinical approach; however, this new perspective requires a shift in the cultural paradigm as well as a reorganization of clinical services in all countries and health systems.

\section{References}

[1] R. Siliquini, 'Medicina Di Genere', CaRe Costi dell'Assistenza e Risorse Econ., pp. 209-224, 2008.

[2] M. Glezerman, 'Discrimination by good intention: Gender-based medicine', Isr. Med. Assoc. J., vol. 11, no. 1, pp. 39-41, 2009.

[3] M. Salmi, 'Gender-specific medicine watch', Pensiero Sci. Ed. downloaded, p. 2020, 2017.

[4] D. Tranfield, D. Denyer, and P. Smart, 'Towards a Methodology for Developing Evidence-Informed Management Knowledge by Means of Systematic Review', Br. J. Manag., vol. 14, pp. 207-222, 2003, doi: 10.1080/16258312.2014.11517339.

[5] S. Kraus, M. Breier, and S. Dasí-Rodríguez, 'The art of crafting a systematic literature review in entrepreneurship research', Int. Entrep. Manag. Journa, vol. 16, pp. 1023 1042, 2020.

[6] C. Okoli, 'A guide to conducting a standalone systematic literature review', Commun. Assoc. Inf. Syst., vol. 37, no. 1, pp. 879-910, 2015, doi: 10.17705/1cais.03743.

[7] N. J. Van Eck and L. Waltman, 'Citationbased clustering of publications using CitNetExplorer and VOSviewer', Scientometrics, vol. 111, no. 2, pp. 10531070, 2017, doi: 10.1007/s11192-017-2300-7.
[8] M. Palmaccio, G. Dicuonzo, and Z. S. Belyaeva, 'The internet of things and corporate business models: A systematic literature review', J. Bus. Res., no. May, pp. 1-9, 2020, doi: 10.1016/j.jbusres.2020.09.069.

[9] M. Bahrampour, A. Bahrampour, M. Amiresmaili, and M. Barouni, 'Hospital service quality - patient preferences - a discrete choice experiment', Int. J. Health Care Qual. Assur., vol. 31, no. 7, pp. 676683, 2018, doi: 10.1108/IJHCQA-01-20170006.

[10] J. Gibbons and M. K. Schiaffino, 'Determining the spatial heterogeneity underlying racial and ethnic differences in timely mammography screening', Int. J. Health Geogr., vol. 15, no. 1, pp. 1-12, 2016, doi: 10.1186/s12942-016-0067-3.

[11] A. Spano, A. Aroni, V. Tagliagambe, E. Mallus, and B. Bellò, 'Performance and expenditure in Italian public healthcare organizations: does expenditure influence performance?', Public Money Manag., vol. 0, no. $0, \quad$ pp. $1-8, \quad 2020$, doi: 10.1080/09540962.2020.1789311.

[12] B. Kordts, J. P. Kopetz, A. Henkel, A. Schrader, and N. Jochems, 'Requirements and Interaction Patterns for a Novel Interaction Device for Patients in Intensive Care', I-Com, vol. 18, no. 1, pp. 67-78, 2019, doi: 10.1515/icom-2019-0004.

[13] D. R. Feikin et al., 'The impact of distance of residence from a peripheral health facility on pediatric health utilisation in rural western Kenya', Trop. Med. Int. Heal., vol. 14, no. 1, pp. 54-61, 2009, doi: 10.1111/j.13653156.2008.02193.x.

[14] E. Hyde et al., 'Estimating the local spatiotemporal distribution of malaria from routine health information systems in areas of low health care access and reporting', Int. J. Health Geogr., vol. 20, no. 1, pp. 1-17, 2021, doi: 10.1186/s12942-021-00262-4.

[15] V. R. Roth, A. Theriault, C. Clement, and J. Worthington, 'Women physicians as healthcare leaders: a qualitative study', $J$. Heal. Organ. Manag., vol. 30, no. 4, pp. 648665, 2016, doi: 10.1108/JHOM-09-20140164.

[16] E. E. Sullivan, Z. Ibrahim, A. L. Ellner, and L. J. Giesen, 'Management lessons for highfunctioning primary care teams', J. Healthc. Manag., vol. 61, no. 6, pp. 449-465, 2016, doi: 10.1097/00115514-201611000-00011. 
[17] G. Tomaselli, L. Garg, V. Gupta, P. A. Xuereb, S. C. Buttigieg, and P. Vassallo, 'Healthcare systems and corporate social responsibility communication:A comparative analysis between Malta and India', J. Glob. Inf. Manag., vol. 26, no. 4, pp. 52-66, 2018, doi: 10.4018/JGIM.2018100104.

[18] R. Gauld and S. Horsburgh, 'Did healthcare professional perspectives on the quality and safety environment in New Zealand public hospitals change from 2012 to 2017?', J. Health Organ. Manag., vol. 34, no. 7, pp. 775-788, 2020, doi: 10.1108/JHOM-112019-0331.

[19] J. Son, P. Flatley Brennan, and S. Zhou, 'A data analytics framework for smart asthma management based on remote health information systems with bluetoothenabled personal inhalers', MIS Quart., vol. 44, no. 1, pp. 285-303, 2020.

[20] R. Ostan, D. Monti, P. Gueresi, M. Bussolotto, C. Franceschi, and G. Baggio, 'Gender, aging and longevity in humans : an update of an intriguing / neglected scenario paving the way to a gender-specific medicine', Clin. Sceince, vol. 130, pp. 17111725, 2016, doi: 10.1042/CS20160004.

[21] G. Biaggio, 'Dalla medicina di genere alla medicina genere-specifica', Ital $J$ GenderSpecific Med, no. 1, pp. 3-5, 2015.

[22] G. Baggio, A. Corsini, A. Floreani, and S. Giannini, 'Gender medicine: a task for the third millennium', vol. 51, no. 4, pp. 713-727, 2013, doi: 10.1515/cclm-2012-0849.

[23] A. Jameton and C. McGuire, 'Toward sustainable health-care services: Principles, challenges, and a process', Int. J. Sustain. High. Educ., vol. 3, no. 2, pp. 113-127, 2002, doi: 10.1108/14676370210422348.

[24] G. Lanza and M. Faini, 'I Sistemi Sanitari'. PROGEA, 2020.

[25] M. A. Ambrosino I, Barbagelata E, Ortona E, Ruggieri A, Massiah G, Giannico OV, Politi $C$, 'Gender differences in patients with COVID-19: a narrative review', Monaldi Arch Chest Dis, vol. 90, no. 2, 2020, doi: doi: 10.4081/monaldi.2020.1389.

[26] A. Gardini and D. Gordini, 'Introduzione alla sostenibilità del sistema sanitario . I pensieri $\mathrm{e}$ la cultura per la qualità sostenibile in medicina ed in sanità', vol. 20. pp. 2-4, 2010.

[27] F. A. Ihantamalala et al., 'Improving geographical accessibility modeling for operational use by local health actors', Int. J.
Health Geogr., vol. 19, no. 1, pp. 1-15, 2020, doi: 10.1186/s12942-020-00220-6.

[28] U. Arul, 'Access to healthcare facilities among the disabled people towards the public healthcare institution', Int. J. Sci. Technol. Res., 2020.

[29] V. Pacáková and P. Jindrová, 'Determinants of health inequalities in European countries', WSEAS Trans. Bus. Econ., vol. 16, pp. 25-38, 2019.

[30] T. Ensor and S. Cooper, 'Overcoming barriers to health service access: Influencing the demand side', Health Policy Plan., vol. 19, no. 2, pp. 69-79, 2004, doi: 10.1093/heapol/czh009.

[31] T. S. O'Connell, K. J. A. Bedford, M. Thiede, and D. McIntyre, 'Synthesizing qualitative and quantitative evidence on non-financial access barriers: Implications for assessment at the district level', Int. J. Equity Health, vol. 14, no. 1, pp. 1-13, 2015, doi: 10.1186/s12939-015-0181-z.

[32] P. Panda et al., 'What Factors Affect Take Up of Voluntary and Community-Based Health Insurance Programmes in Low- and MiddleIncome Countries? Protocol', SSRN Electron. $J$. no. September, 2015, doi: 10.2139/ssrn.2656059.

[33] J. D. Sachs, 'Achieving universal health coverage in low-income settings', Lancet, vol. 380 , no. 9845 , pp. 944-947, 2012, doi: 10.1016/S0140-6736(12)61149-0.

[34] World Health Organization, 'WHO guideline on health policy and system support to optimize community health worker programmes', 2018.

[35] T. T. Awoyemi, O. A. Obayelu, and H. I. Opaluwa, 'Effect of Distance on Utilization of Health Care Services in Rural Kogi State, Nigeria', J. Hum. Ecol., vol. 35, no. 1, pp. 19, 2011, doi: 10.1080/09709274.2011.11906385.

[36] P. W. Gething et al., 'Geographical access to care at birth in Ghana: A barrier to safe motherhood', BMC Public Health, vol. 12, no. 1, p. 1, 2012, doi: 10.1186/1471-2458-12991.

[37] C. Hanson et al., 'Access to maternal health services: Geographical inequalities, united republic of Tanzania', Bull. World Health Organ., vol. 95, no. 12, pp. 810-820, 2017, doi: 10.2471/BLT.17.194126.

[38] K. Munguambe et al., 'Barriers and facilitators to health care seeking behaviours in pregnancy in rural communities of southern Mozambique', Reprod. Health, vol. 13, no. 1, 2016, doi: 10.1186/s12978-016-0141-0. 
[39] L. Artazcoz, C. Borrell, and J. Benach, 'Gender inequalities in health among workers: The relation with family demands', J. Epidemiol. Community Health, vol. 55, no. 9, pp. 639-647, 2001, doi: 10.1136/jech.55.9.639.

[40] L. Harryson, M. Novo, and A. Hammarström, 'Is gender inequality in the domestic sphere associated with psychological distress among women and men? Results from the Northern Swedish Cohort', J. Epidemiol. Community Health, vol. 66, no. 3, pp. 271-276, 2012, doi: 10.1136/jech.2010.109231.

[41] C. Facchini et al., 'Salute e disuguaglianze', Fr. Angeli, pp. 5-6, 2001.

[42] A. S. Warner and L. S. Lehmann, 'Gender Wage Disparities in Medicine: Time to Close the Gap', J. Gen. Intern. Med., vol. 34, no. 7, pp. 1334-1336, 2019, doi: 10.1007/s11606019-04940-9.

[43] C. Aneshensel, 'Social Stress: Theory and Research', Annu. Rev. Sociol., vol. 18, no. 1, pp. 15-38, 1992, doi: 10.1146/annurev.soc.18.1.15.

[44] E. Wilson, Social Determinants of Health : A Public Health Issue. 2005.

[45] I. Mishchuk, O. Zinchenko, D. Zinchenko, P. Darius, and A. Pohrebniak, 'Differences in the Assessment of Economic Security of Personnel and Security of Enterprise Staff Interests Mayor of city Gromadka', WSEAS Trans. Environ. Dev., vol. 16, pp. 454-463, 2020, doi: 10.37394/232015.2020.16.46.

[46] S. Kalaitzi et al., 'Women, healthcare leadership and societal culture: A qualitative study', J. Healthc. Leadersh., vol. 11, pp. 4359, 2019, doi: 10.2147/JHL.S194733.

[47] M. Al-Amin, M. K. Schiaffino, S. Park, and J. Harman, 'Sustained hospital performance on hospital consumer assessment of healthcare providers and systems survey measures: What are the determinants?', J. Healthc. Manag., vol. 63, no. 1, pp. 15-28, 2018, doi: 10.1097/JHM-D-16-00006.

[48] M. Marmot, 'Status syndrome', Significance, vol. 1, no. 4, pp. 150-154, 2004, doi: 10.1111/j.1740-9713.2004.00058.x.

[49] D. Blane, 'An assessment of the Black Report's explanations of health inequalities', Sociol. Health Illn., vol. 7, no. 3, pp. 423-445, 1985, doi: 10.1111/1467-9566.ep10832355.

[50] TI, 'I rischi psicosociali : definizione e misure di prevenzione', 2020.

[51] R. Biancheri, 'The transversality of the gender approach to health and safety at work. From theory to practice of a possible interaction', Salut. e Soc., no. 1, pp. 127-141, 2014, doi: 10.3280/ses2014-001011.
[52] R. Biancheri, 'Dalla medicina di genere al genere in salute', Salut. e Soc., 2014.

[53] L. Pavlík, E. Chytilová, and J. Zimmermannová, 'Security aspects of healthcare organization from the perspective of digitization of facility management', WSEAS Trans. Bus. Econ., vol. 18, pp. 360366, 2021, doi: 10.37394/23207.2021.18.36.

[54] M. Xiang, Y. He, H. Zhang, C. Zhang, Z. Zeng, and B. An, 'Circuit Health State Estimation via An Integrated Deep Neural Network', Int. J. Circuits, Syst. Signal Process., vol. 14, pp. 661-668, 2020, doi: 10.46300/9106.2020.14.85.

[55] A. Mukred, D. Singh, and N. Safie, 'Investigating the impact of information culture on the adoption of information system in public health sector of developing countries', Int. J. Bus. Inf. Syst., vol. 24, no. 3, pp. 261-284, 2017, doi: 10.1504/IJBIS.2017.082036.

[56] R. C. Beckett, 'Hearing enhancement technologies and issues of self-management: A case study', Int. J. Technol. Mark., vol. 12, no. 3, pp. 252-273, 2017, doi: 10.1504/IJTMKT.2017.089648.

[57] P. Sivaranjani, M. Agalya, A. Ayisha, and S. Abinanth, 'Automatic medicine teller', Int. J. Sci. Technol. Res., vol. 9, no. 2, pp. $1517-$ 1520, 2020.

[58] D. G. Schwartz, A. Bellou, L. GarciaCastrillo, A. Muraro, and N. Papadopoulos, 'Exploring mHealth participation for emergency response communities', Australas. J. Inf. Syst., vol. 21, pp. 1-17, 2017, doi: 10.3127/ajis.v21i0.1378.

[59] N. Liu, Y. Tong, and H. C. Chan, 'Dual effects of social support seeking in patientcentric online healthcare communities: A longitudinal study', Inf. Manag., vol. 57, no. $8, \quad$ p. $103270, \quad 2020, \quad$ doi: 10.1016/j.im.2020.103270.

[60] L. Synyayeva, D. Verba, A. Yarchuk, I. Verkhovod, and D. Aleksandrov, 'Resources of educational and healthcare industries and population welfare: Comparative analysis in post-socialist and oecd countries', WSEAS Trans. Bus. Econ., vol. 18, pp. 531-542, 2021, doi: $10.37394 / 23207.2021 .18 .54$.

Author Contributions: All authors have read and agreed to the published version of the manuscript. Funding: This research received no external funding

\section{Creative Commons Attribution License 4.0 (Attribution 4.0 International, CC BY 4.0)}

This article is published under the terms of the Creative Commons Attribution License 4.0

https://creativecommons.org/licenses/by/4.0/deed.en_US 